\title{
THE BIOLOGY OF THE PRAWN, PALAEMON (=LEANDER) SERRATUS (PENNANT)
}

\author{
BY G. R. ForSTER \\ The Plymouth Laboratory
}

In a recent paper Cole (1958) has offered a new interpretation of the results obtained in 1949 and 1950 during my investigations of the biology of prawns. The present paper is the outcome of a re-examination of these results and of further prawn measurements which were continued on a small scale until 1955. The later investigations consisted of an annual survey of the prawns, particularly the O-group, caught from the rocks on the south side of the R.A.F. Station, Mount Batten, usually during the first low spring tides every October. The total number of prawns measured in the whole period was over 8,600 .

\section{THE 1949 AND 1950 SAMPLES}

The length measurements of the prawns caught during a I2-month period, starting in October 1949, have been re-analysed into millimetre instead of $\frac{1}{2}$-centimetre groups and the results plotted on probability paper. As Harding (1949) has pointed out, this paper can help considerably in the analysis of polymodal samples; though with the prawn's long breeding season one cannot necessarily expect year-groups to be sharply defined. During the winter, catches have been combined and plotted at monthly or bimonthly intervals, but during the summer when rapid growth may occur it was found desirable to limit the inclusive period for any one group to a maximum of about a fortnight.

The results are shown in Fig. I, with the different symbols indicating my interpretation of the year-groups. The appearance of the O-group prawns in August and September can be clearly distinguished both with males and females. In July and August there were also many tiny prawns taken by a stramin net which could not be sexed. These have not been included.

The September samples of the O-group appear in Fig. I as reasonably straight lines, i.e. showing a normal distribution. But by October, after further growth and recruitment, the population has been widely spread and when plotted can be considered as two or three separate but overlapping populations. These populations probably represent fluctuations in the numbers of larvae settling in the early part of the summer. A separate late 'brood' in the smallest stages is clearly shown with the males in October 1949, and with the females in October I950. Cole (I958, p. 20) preferred to consider these $3-\mathrm{cm}$ prawns as the true O-group; but they only represent about 


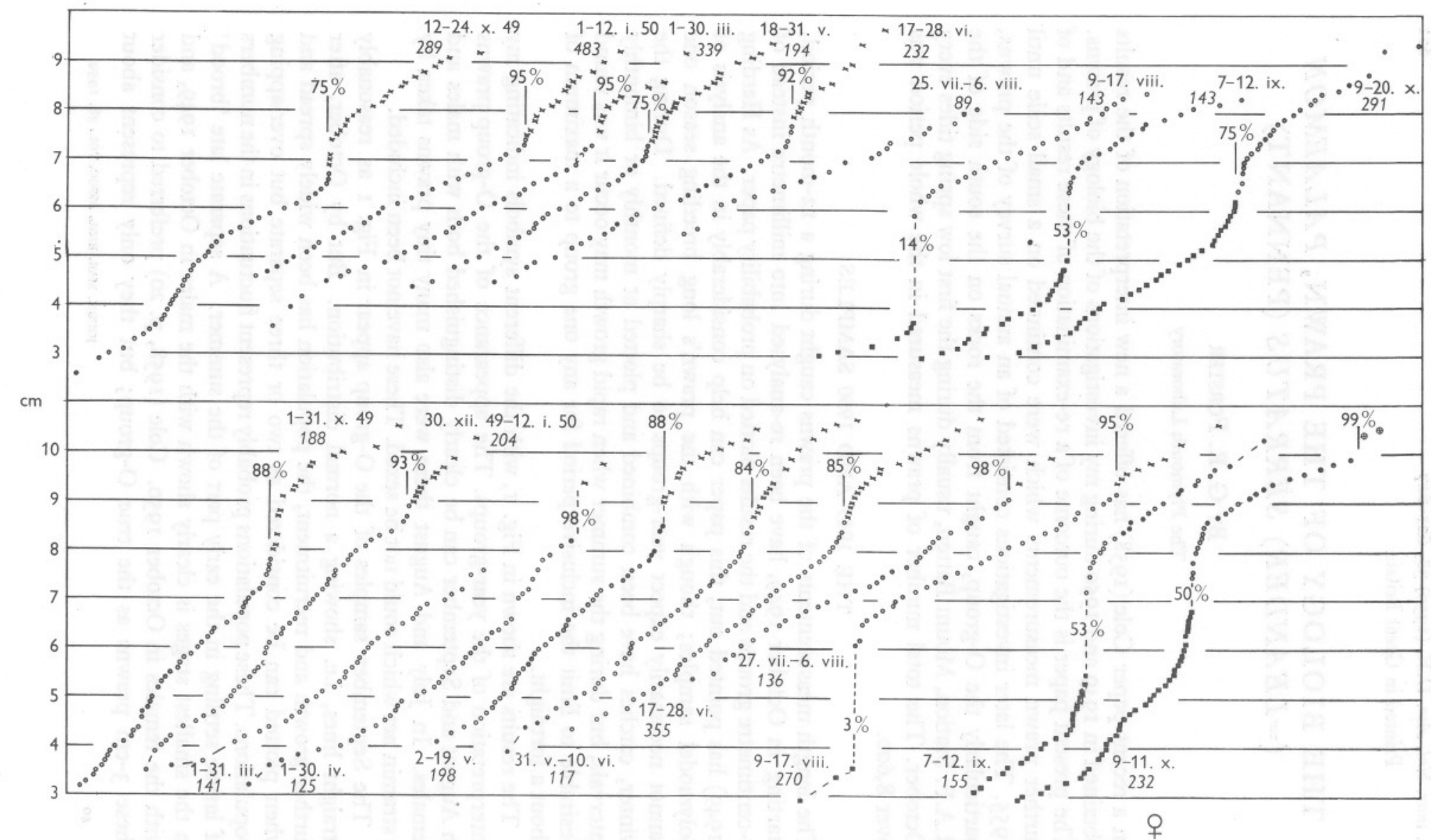

Fig. I. Catches of male and female prawns in 1949 and 1950 plotted as cumulative percentages on log scale (probability paper). The year-groups from 1948-50 are represented by crosses, open circles and solid dots respectively. 
$5 \%$ of the total catch, and are even smaller than the clearly defined O-group of later, colder years. The 1949 males soon grew sufficiently to merge with the main bulk of the O-group. The exceptionally warm conditions during the spring and summer of 1949 probably led to a very early settlement of larvae, beginning in May or June. Lebour (1947), during her 1940-5 investigations, found larvae all the year round except in November and December, but with the greatest numbers in June, July and August.

The sequence of replacement of the 1948 and 1949 year-groups can be seen in Fig. I and calls for no detailed re-description. It is possible that some of the prawns included in the 1948 year-group might in fact be somewhat older; in particular the January I950 catch of males shows two populations at $8 \mathrm{~cm}$ and $9 \mathrm{~cm}$ but these numbers are very small; the distinction is not evident for several months and the whole group disappear from the catches after the end of June. The I948 group females continued to appear in the August samples, i.e. after their third birthday. But they too had apparently died off by mid-September, though two at $10.4 \mathrm{~cm}$ and $10.5 \mathrm{~cm}$ caught in October might represent the last survivors; however, they form only $\mathrm{I} \%$ of the total sample.

\section{CATCHES FROM 1951-1955}

In 1952 and 1955 only the O-group were sampled, but for the other three years large as well as small size-groups were measured. The results are shown in histogram form in Fig. 2. Both males and females exhibit very clear bimodal distributions, the O-group appearing at $3-4 \mathrm{~cm}$ and the I-year-old at $7-8 \mathrm{~cm}$. The I-year-old females have outgrown the males by about $\mathrm{I} \mathrm{cm}$. In $195 \mathrm{I}$ there is a small 'tail' of very large prawns. When their distribution is plotted on probability paper, these prawns show up clearly as a separate group and are presumably the few surviving 2-year-olds. Their numbers have dwindled to less than $2 \%$ of the total. The various O-group distributed in Fig. 2 are all much smaller than their counterparts in I949-50 but correspond closely to the results of Cole from $\mathrm{N}$. Wales in the same period. The mean lengths of the O-group for each year I949 to 1955 have been extracted and plotted together with the sea temperature in Table I.

The figure for 1952 is approximate as only the percentages of each $\frac{1}{2}-\mathrm{cm}$ group were available, the original measurements having been lost. The temperatures have been taken from Cooper (1958). From the Table it can be seen that there is a general agreement between the temperatures and lengths particularly in the two warmer years I 949 and I950. Mr. G M. Spooner had kindly undertaken a statistical analysis of the figures and has found a significant correlation between them.

Fig. 2 also shows a sample of prawns taken in July 1954. In both sexes there are two distinct year-groups which are assumed to be those of 1953 and 1952, with the 1953-group females having grown considerably since the 


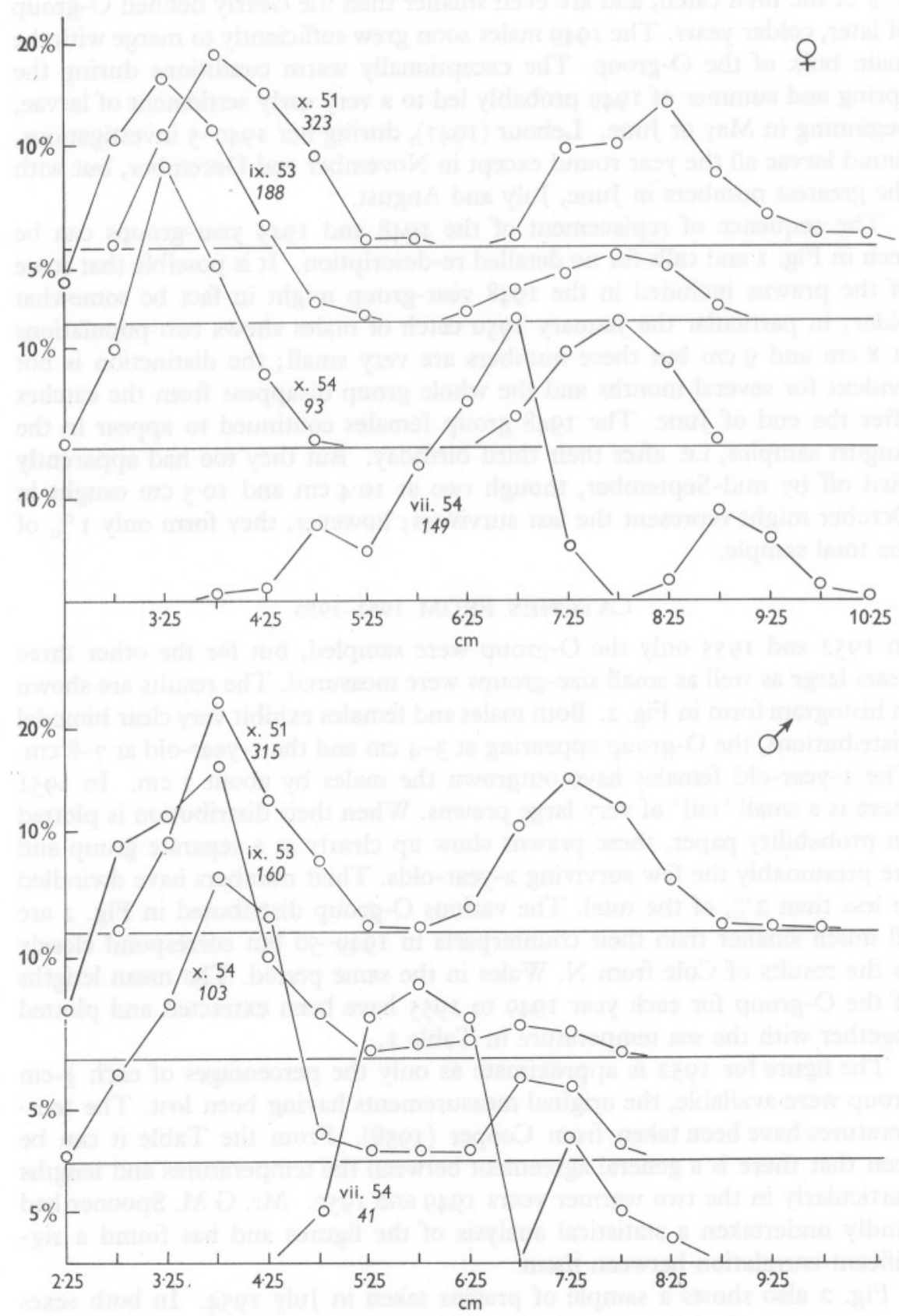

Fig. 2. Samples of male amd female prawns from Rum Bay, $195 \mathrm{I}-4$, in $\frac{1}{2}-\mathrm{cm}$ groups. 
previous autumn. Table 2 gives the breeding condition of these female prawns.

It is very probable that some of the non-breeding prawns about $6 \mathrm{~cm}$ in length had already hatched one brood, and also the two-year-olds $(7-8 \mathrm{~cm})$ would be carrying their second brood.

\begin{tabular}{|c|c|c|c|c|}
\hline Year & $\begin{array}{l}\text { Mean length } \\
\text { of O-group. } \\
\text { Oct. sample } \\
\delta+q\end{array}$ & $\begin{array}{l}\text { No. } \\
\text { in } \\
\text { sample }\end{array}$ & $\begin{array}{c}\text { Difference } \\
\pm 39 \mathrm{~mm} \\
(\mathrm{~mm})\end{array}$ & $\begin{array}{l}\text { Agg. } \\
\text { temp. } \\
\left({ }^{\circ} \mathrm{C}\right)\end{array}$ \\
\hline $\begin{array}{l}\text { I949 } \\
\text { I950 }\end{array}$ & $\begin{array}{l}56 \cdot 1 \\
47 \cdot 5\end{array}$ & $\begin{array}{l}366 \\
332\end{array}$ & $\begin{array}{l}+17 \cdot I \\
+8.5\end{array}$ & $\begin{array}{l}+9.6 \\
+3.6\end{array}$ \\
\hline 1951 & 38.6 & 354 & -0.4 & -2.8 \\
\hline 1952 & $39 \cdot 9$ & & +0.9 & $+\mathrm{r} \cdot 4$ \\
\hline 1953 & 35.9 & 104 & $-3 \cdot I$ & -0.6 \\
\hline I954 & 35.5 & I 48 & -3.5 & $-3 \cdot 2$ \\
\hline 1955 & 37.9 & 197 & $-I \cdot I$ & $-\mathrm{I} \cdot 8$ \\
\hline
\end{tabular}

* Temperature heading: aggregate differences of each monthly mean sea temp. for MarchOctober from ro-year average $1947-56$.

\section{TABLE 2. PRAWNS CAUGHT ON 2 JULY 1954}

\begin{tabular}{|c|c|c|c|c|}
\hline $\begin{array}{c}\text { Length } \\
(\mathrm{cm})\end{array}$ & $\begin{array}{c}\text { Non-` } \\
\text { breeding }\end{array}$ & $\begin{array}{c}\text { Total } \\
\text { berried }\end{array}$ & $\begin{array}{c}\text { Berried with } \\
\text { eggs near } \\
\text { hatching }\end{array}$ & Cemented \\
\hline $3.5-3.9$ & I & 0 & 0 & 0 \\
\hline $4 \cdot 0-4 \cdot 5$ & 2 & 0 & 0 & 0 \\
\hline $4 \cdot 5-4 \cdot 9$ & II & o & o & 0 \\
\hline $5 \cdot 0-5 \cdot 4$ & 7 & 0 & 0 & 0 \\
\hline $5 \cdot 5-5 \cdot 9$ & 8 & II & 3 & I \\
\hline $6 \cdot 0-6 \cdot 4$ & 12 & I6 & 9 & I \\
\hline $6 \cdot 5-6 \cdot 9$ & 23 & 17 & II & 2 \\
\hline $7 \cdot 0-7 \cdot 4$ & 4 & 3 & 3 & I \\
\hline $7 \cdot 5-7 \cdot 9$ & 0 & 0 & 0 & 0 \\
\hline $8 \cdot 0-8 \cdot 4$ & 0 & 3 & 0 & 0 \\
\hline $8.5-8.9$ & 4 & 9 & I & o \\
\hline $9 \cdot 0-9.4$ & o & 8 & I & I \\
\hline $9.5-9.9$ & 0 & 2 & I & 0 \\
\hline $10.0-10.4$ & 0 & I & I & I \\
\hline
\end{tabular}

The I953 year-group will have spawned in April or May and must therefore have continued to grow rapidly in the late autumn. Its mean length in July was $6 \mathrm{r} \mathrm{mm}$. The small non-breeding prawns would have been growing in May and June as would the larger ones after hatching their eggs, so the mean length of the whole group may be estimated at about $55 \mathrm{~mm}$ before spawning. The group therefore grew from a mean length of $32 \mathrm{~mm}$ at the end of September to $55 \mathrm{~mm}$ in the spring. At first sight this might appear an impossibly high rate of growth for the colder part of the year. However, in the fortnight from September 1953, when the sample was taken, until 9 October, the mean length of the group increased by $4 \mathrm{~mm}$; as the sea temperature did not decline rapidly until January, a length of 50-55 $\mathrm{mm}$ might well have been attained by the end of December. 


\section{DISCUSSION}

Apart from the particularly warm years 1949 and 1950 the growth rate of prawns at Plymouth is comparable to that found by Cole (1958) in N. Wales. The O-group in October averages about $38 \mathrm{~mm}$ total length and $7 \mathrm{~mm}$ carapace length. There is a marked difference in the age at which the female prawns mature. Whereas in Wales only a few females breed in their first year, at Plymouth the bulk of the female population spawn before their first birthday.

The breeding period seems, in general, to be a little earlier than that found by Cole (1958) at Holyhead in 1953, but much later than at Plymouth in the warmer year, 1950. By their second October there is little difference in size between the Plymouth prawns and their Welsh counterparts.

Cole (1958) questions my earlier interpretation of the autumn 1949 and I950 catches, maintaining that it involved an impossibly high growth rate because of a large size difference between samples at the end of August and the early part of September. But the August samples were taken with a stramin net which would not catch nearly as many of the $3-4 \mathrm{~cm}$ prawns as the normal hand net with $\frac{1}{2}$ in.-mesh netting. The O-group samples taken in August, September and October shown in Fig. I present a consistent pattern of moderately rapid growth, together with an increasing spread as later settling juveniles come into the samples. Nor is there any trace of the group suggested by Cole to lie between my O-group-I-year-old group, either in 1949-50 (Fig. I) or in the later years, Fig. 2.

With regard to the older prawns which Cole considers to live several years longer than at Plymouth, it is difficult to follow the interpretation of his results. Concerning the males (p. 12) he states 'a group of prawns completing their second year with a peak at $\mathrm{I} 3.0-\mathrm{I} 4.2 \mathrm{~mm}$ in June can also be discerned,' but in the next paragraph Cole describes 'the group at $14.8 \mathrm{~mm}$ in June as attaining 3 years in July.' In my view these groups are so similar in size that they should both be considered as nearly two years old. Similarly with the female prawns it seems that 'the strong group about $16.6 \mathrm{~mm}$ in June' described on p. I5 could more reasonably be regarded as nearly two years old rather than three. Cole describes his fig. I3 as providing clear evidence of the existence of at least 5 year-groups, even though the older groups are merged, but by comparison with his fig. I 2 the main bulk of catch in fig. I3 (October-November) would seem to be composed of I and 2-year-olds and the few larger prawns both in this and other samples of female prawns would, to my mind, be more reasonably taken as the remnants of the 3-year-old group rather than 4 or 5-year-olds. The largest prawns of all might well be somewhat older but they form a very small proportion of the catches. 


\section{SUMMARY}

Data on the age and growth of the prawn Palaemon serratus (Pennant) collected in 1949 and I950 have been re-examined in the light of further investigation at Plymouth from I95I-5 and of Cole's results from North Wales. Contrary to Cole's view the original interpretation of the growth rate is considered to be valid.

The length of the O-group in October is significantly correlated with the sea temperatures from March till October. Growth rates of the Plymouth and North Wales population are similar but the females mature much sooner at Plymouth. The age reached by the $\mathrm{N}$. Wales prawns is thought to be rather less than Cole has suggested.

\section{REFERENCES}

Cole, H. A., I958. Notes on the biology of the common prawn. Fish. Invest., London, Ser. 2, Vol. 22, No. 5

CoOPER, L. H. N., 1958. Sea temperatures in Plymouth Sound. F. mar. biol. Ass. U.K., Vol. 37, pp. I-3. 22 pp.

Forster, G. R., I95I. The biology of the common prawn, Leander serratus Pennant. F. mar. biol. Ass. U.K., Vol. 30, pp. 333-60.

HARDING, J. P., I949. The use of probability paper for the graphical analysis of polynodal frequency distributions. F. mar. biol. Ass. U.K., Vol. 28, pp. I4I-53.

Lebour, M. V., I947. Notes on the inshore plankton of Plymouth. F. mar. biol. Ass. U.K., Vol. 26, pp. 527-47. 